RESEÑAS

\title{
Yo te creo: Testimonios de abuso a mujeres chilenas
}

\author{
Abril Silva \\ Universidad de Chile
}

I Nona Fernández, Macarena García, Sofía Garabito, Paulina García y Rayén Araya, Yo te creo: Testimonios de abuso a mujeres chilenas. Santiago: Alquimia, 2019, 95 páginas.

Yo te creo: Testimonios de abusos a mujeres chilenas es como se titula el libro que publicado en mayo de 2019 por la editorial Alquimia. Se caracteriza por un fuerte contenido testimonial de diversas experiencias de mujeres que han sufrido violencia machista. Como es sabido, la misoginia pude ser ejercida desde múltiples ámbitos y expresarse también de diversas formas. Todos los relatos que en este libro se tejen están narrados por mujeres que han sufrido agresiones sexuales de forma directa, en diferentes contextos, como la calle, el transporte público, reuniones familiares y - como se cuenta al final del libro- bajo tortura por agentes estatales en dictadura.

La importancia de este libro y la necesidad de su lectura radica en el potente mensaje que entrega, el cual está configurado de forma explícita en su título, Yo te creo. Los orígenes de esta consigna pueden rastrearse hacia el año 2016 con la campaña que surgió en España tras el caso tristemente conocido como «La Manada», en el cual un grupo de hombres violaron y golpearon a una chica de dieciocho años durante la Fiesta de San Fermín. La primera sentencia sobre este caso fue muy polémica porque, a pesar de ser condenatoria, en ella el tribunal dio una calificación jurídica de los hechos en la cual descartaba una condena por el delito de violación. Este pronunciamiento judicial generó gran indignación en la comunidad y, como consecuencia de ella, surgió la campaña a través de Twitter con el hashtag «\#YoSiTeCreo» frase que, gracias al eco de las redes sociales, se extendió por gran parte del mundo occidental, formando parte de las consignas que más se repitieron en lo que posteriormente se conocería como la «ola feminista».

1. Finalmente, el 5 de junio de 2019, el Tribunal Supremo español emitió una sentencia que establece 
De este modo, lo valioso del libro se reafirma con lo acertado de su nombre. Pues tal como la frase a la que se hace referencia, nace como una manifestación de un sentimiento de sororidad para con la víctima del caso La Manada. El libro nos invita a una reflexión íntima y desnuda por las traumáticas experiencias de las mujeres que escriben. Es también una invitación a creer en la palabra de la denunciante, a validar la experiencia de la otra, y así permitirle moverse desde la confianza. Esto es sustancial, porque quienes hemos sido víctimas de violencia de género sabemos que la confianza es lo primero que una mujer pierde. Se pierde la confianza en continuar viviendo con normalidad, en caminar tranquila por las calles, en las relaciones que una tenga con otros hombres, entre otras muchas confianzas que se desvanecen luego de una experiencia de este tipo.

Sin embargo, tal vez más terrible que la pérdida de la confianza referida — por lo funesto que es para un Estado democrático de derecho- es la pérdida de confianza que se genera en la institucionalidad, específicamente en el aparato judicial, debido a la nula aptitud del sistema jurídico para absorber, acoger y entregar justicia a las mujeres víctimas de este tipo de violencia. La burocracia, la revictimización, la falta de una perspectiva de género en los actores del sistema y el alto estándar probatorio se mezclan para terminar de fraguar una pesadilla ya no solo personal en la mujer violentada, sino que institucional, con tintes kafkianos. Estas son algunas de las muchas razones que hay para que las víctimas prefieran no denunciar y continúe la impunidad de sus agresores: la falta de alguien que, cuando van a denunciar, les diga «yo te creo».

A pesar de lo anterior, lo más interesante de la consigna sorora que sirve de título para el libro que comentamos es que hace referencia a una carencia anterior y no tan solo jurídica, a saber, una carencia que llamaré material. Quienes enarbolan esta poderosa frase no plantean entregar una respuesta unívoca a la disyuntiva que plantea el conflicto que se genera con una denuncia, entre el derecho al acceso a la justicia que tiene la víctima con el derecho que tiene el acusado a su presunción de inocencia y un debido proceso.

En contra de cómo se ha intentado caricaturizar, en la frase "yo te creo» hay más un llamado a la sociedad que a los legisladores y actores jurídicos, implica una invitación a que la comunidad pueda brindarle a la víctima confianza, seguridad y apoyo que contribuya a evitar el doble trauma que implica haber vivido una experiencia así y que, además, ésta sea puesta en duda. Cuando creemos estamos validando y generando confianza en la víctima, implica darle credibilidad a su relato para que ella tenga un respaldo al denunciar este tipo de agresiones, y definitivamente generar esta seguridad en ella es el primer paso que constituye la base para iniciar un proceso

una verdad jurídica fiel a la verdad material, pues fue condenada La Manada a quince años por el delito de violación. 
de reparación que desemboque en la sanación y en la paz. Por lo tanto, mientras no haya reformas estructurales del Estado para enfrentar la violencia de género, bien podríamos empezar nosotros, desde la sociedad, a generar el cambio, diciendo fuerte y claro: yo te creo.

Para generar estas reflexiones, el libro se divide en dos secciones. La primera parte comprende cinco historias de violencia sexual. Estas experiencias son narradas en primera persona por las protagonistas reales: la escritora y actriz Nona Fernández Silanes (Mapocho, Av. 10 de julio Huamachuco); la escritora, editora y académica Macarena García Moggia (Aldabas, Maratón); la artista visual, pedagoga y dibujante Sofía Garabito (Un cuarto propio, Brígida); la actriz nacional, directora de teatro y dramaturga Paulina García Alonso (Gloria, Las analfabetas), y la periodista nacional con larga trayectoria en distintos medios de comunicación, Rayen Araya.

La narración de estas experiencias plasma un potente mensaje de denuncia, que se va tejiendo en forma de relato coral por dichas mujeres, pero todo tejido y elaboración de un mensaje potente requiere un proceso que no está exento de dificultades. Porque si bien el primer paso para iniciar un tejido es enhebrar, en este caso enhebrar implica desenterrar traumas que esta sociedad ha optado por normalizar, ridiculizar o invisibilizar; y para hallar este tipo de recuerdos primero es necesario armarse de coraje. Escarbar en la tierra para recordar, que, como nos recordó Eduardo Galeano en El libro de los abrazos, viene del latín re cordis, que significa «volver a pasar por el corazón». Estamos ante mujeres valientes, porque en este ejercicio ellas han traído al presente dolores, miedos, incomodidades, traumas y una multiplicidad de sentimientos inefables que todo instinto de sobrevivencia muchas veces opta por suprimir y relegar al pasado. Pero, con este libro, ellas demuestran que tal dificultad no es óbice para lograr tejer con palabras los recuerdos y así darle voz a lo que fue por mucho tiempo algo indecible.

Virginia Woolf escribía que «una mujer debe tener dinero y una habitación propia para poder escribir» ${ }^{2}$ constatando así el hecho de que para que una mujer pueda escribir, debe ser poseedora de ciertos privilegios. En este sentido el libro representa la concreción de la voz que emana de las habitaciones propias de las mujeres que ahí comparecen, permitiéndoles plasmar una experiencia dolorosa a través de un proceso creativo, que posteriormente culmina en una obra de arte y que a su vez constituye una dimensión que puede abrir camino a la sanación. Esta primera sección precisamente consta de relatos de mujeres que poseen reconocimiento público, profesionales y "empoderadas". Sin embargo, lejos esto de convertirse en un obstáculo para la identificación de las lectoras con las narradoras, es probablemente su mayor virtud, al invitar con fuerza a reflexionar sobre la transversalidad de la violencia de géne-

2. «Una habitación propia», de Virginia Woolf, es un ensayo basado en dos conferencias dadas en octubre de 1928 en la Sociedad Literaria de Newham y la Odtaa de Girton. 
ro. Estamos ante mujeres que poseen el privilegio de «una habitación propia»y, no obstante, son también víctimas de la barbarie falócentrica. Entonces surge legítimamente la pregunta sobre ¿Qué queda para aquellas que por no tener un cuarto propio no tienen voz? Aquellas hijas de nadie, dueñas de nada (de nuevo Galeano) que son obligadas a cargar solas con sus traumas.

La segunda parte del libro, podría ser un intento de subsanar aquel sesgo que posee la primera parte, ya que es una recopilación de testimonios anónimos que han sido extraídos del Observatorio contra el Acoso Callejero (OCAC) y del Informe de la Comisión Valech.

Los relatos contemporáneos del Observatorio contra el Acoso Callejero develan aquellos micromachismos que día a día experimentamos las mujeres, que muchas veces la sociedad decide invisibilizar al establecer que son practicas normales y comunes, pero hace tiempo que ya nadie puede ignorar que no por cotidianas que puedan ser dejan de representar un problema que cala profundo en nuestra sociedad. En el mismo hecho de esconderse como trivialidades se refleja el inequívoco contenido ideológico de tales prácticas que, lejos de cualquier fraude de etiquetas, se llama acoso callejero y violencia patriarcal.

Por otro lado, los relatos recopilados del informe de la Comisión Valech son narraciones hechas por ex presas políticas sobrevivientes a la dictadura cívico-militar (1973-1990), las cuales son desgarradoras por su brutalidad, por intentar decir con palabras aquella violencia que quiebra cualquier reconocimiento, base fundamental del lenguaje. En sus testimonios queda de manifiesto que es muy diferente ser presa política a ser preso político, ya que las prácticas ejercidas contra las mujeres eran muy diversas a las ejercidas contra los hombres: la tortura política para las mujeres se caracterizaba por ser intrínsecamente sexual, coincidente con el contenido de los insultos callejeros.

Las atrocidades cometidas por agentes del Estado no tienen parangón. Esto da cuenta de que la magnitud de la violencia de género es distinta cuando es ejercida por el aparato estatal, ya que en lo particular se trataba de personas que eran contratadas como funcionarios públicos con una única función, la cual consistía en ejercer el rol de represión a través de la tortura. Una política de gobierno llevada a cabo de forma sistemática, lo narrado en estas páginas constituye violaciones a los derechos humanos.

Los testimonios de esta segunda parte fueron puestos en páginas de color negro, y la estética del libro en esta sección parece responder a un mensaje bastante claro: responde a una época negra, ya que hoy continúa existiendo mucha oscuridad con respecto a lo ocurrido, los torturadores y gran parte de la institucionalidad y gobiernos de turno luego de la dictadura han logrado oscurecer la verdad para que muchos de los responsables hoy vivan impunes. 
Continuando en la misma línea sobre la edición, estamos ante un libro artefacto, que resulta atractivo no solo por su contenido, sino también por su estética, que es rupturista también de forma visual. En la primera sección hay fotografías en primer plano de cada una de las autoras que construye su testimonio. En el libro podemos apreciar sus rostros, los cuales se presentan muy decidores, porque vemos ahí mujeres reales, con gesto serio, lo cual permite lograr una conexión emocional para quien las lee, brindando la oportunidad de mirarlas a los ojos y sintonizar con sus historias y sus dolores. Al leerlas podemos verlas y así entenderlas, aceptando y haciendo nuestra la consigna que lleva como título el libro, creyendo esa verdad, una que se muestra sin tapujos, sin maquillaje, que es presentada de forma sólida y directa.

En fin, cada testimonio es conmovedor, es un balde de agua fría que eriza los pelos y riega las semillas que se encuentran latentes en la memoria de -me imagino- la mayoría de las lectoras, es muy probable que la lectura de este libro haga que dichas semillas broten y haga aflorar recuerdos de experiencias similares, recuerdos que todas deberíamos mantener a flor de piel, para no olvidar que nos atraviesa una historia en común.

\section{Sobre la autora}

Abril Silva es estudiante de Derecho de la Universidad de Chile, pasante del Centro de Derechos Humanos de la misma universidad y asistente editorial del Anuario de Derechos Humanos. 
